\title{
Species composition, distribution patterns and ecological functions of biological soil crusts in the Gurbantunggut Desert
}

\author{
YuanMing ZHANG ${ }^{*}$, Nan WU, BingChang ZHANG, Jing ZHANG \\ Key Laboratory of Biogeography and Bioresource in Arid Land, Xinjiang Institute of Ecology and Geography, Chinese Academy \\ of Sciences, Urumqi 830011, China
}

\begin{abstract}
As one of the most important biological factors that maintain the stability of the largest fixed and semi-fixed desert in China, the Gurbantunggut Desert, the biological soil crusts (BSCs) develop well and play critical ecological roles in the desert ecosystem. In this paper, we briefly summarize our research findings since 2002 including species composition, distribution pattern and ecological functions of BSCs in the desert. Our results indicate abundant species diversity of BSCs in the Gurbantunggut Desert in comparison to other deserts in China. At the scales of sand dune or whole desert, the distribution patterns of BSCs are location-specific. The existence of BSCs in this desert could: (1) accelerate the formation of desert soil and the weathering of minerals; (2) accumulate organic matter in surface soil through related species in soil crusts; (3) enhance the abilities of sand surface to resist wind erosion; (4) influence seed germination of vascular plants; and (5) enhance the production of dew deposition on sandy soil surface.
\end{abstract}

Keywords: biological soil crusts; species diversity; location-specific distribution; desert ecosystem

\section{Introduction}

Arid and semi-arid lands usually come with a sparse or even absent coverage of vegetation. Nevertheless, in open spaces between the vascular plants, the soil surface is generally covered by a community of highly specialized organisms, such as mosses, lichens, liverworts, algae, fungi, cyanobacteria and bacteria. These communities are usually referred to biological soil crusts (BSCs), or cryptogamic, crytobiotic, microbiotic, microphytic soil crusts (Harper and Marbel, 1988; West, 1990). BSCs, given their extraordinary abilities to avoid desiccation and survive in extreme temperatures (up to $70^{\circ} \mathrm{C}$ ), high $\mathrm{pH}$, and high salinity environments, have been found in desert areas all over the world and may constitute as high as $70 \%$ of the living cover in some plant communities (Friedmann and Galun, 1974; West, 1990). BSCs play a vital role to ensure proper structuring and functioning of desert ecosystems, such as engagement in the process of soil formation, stability and fertility, prevention from soil erosion caused by wind or water, augmentation of vascular plant colonization, and stabilization of sand dunes (Eldridge and Greene, 1994; Belnap and Lange,
2001; Belnap, 2003; Zhang et al., 2006; Li et al., 2009). Recently, the issue of crust recovery from various kinds of destruction such as global warming and intensified human activities has been researched in a few desert ecological studies (Belnap and Eldridge, 2001; Belnap et al., 2008). As a result, Belnap (2003) has recognised preserving BSCs as the top management priority in desert regions.

The Gurbantunggut Desert is the biggest fixed and semi-fixed desert in China. Several factors have been suggested as main contributors for sandy surface stability, such as suitable size of substrate materials, sufficient snow cover in winter and occurrence of ephemerals in early spring (Wang et al., 2003; Qian et al., 2007). But there is no concrete proof to support the view that substrate materials are responsible for the sandy soil surface stability. Snow cover and growth of ephemerals only occurred in certain short seasons, and, therefore, cannot explain surface stability during long dry summer and autumn seasons. For a long time the

Received 2010-04-26, accepted 2010-06-18

doi: 10.3724/SP.J.1227.2010.00180

Cooresponding author: YuanMing ZHANG (E-mail: zhangym@ms.xjb.ac.cn) 
stabilizing effect of BSCs on sandy soil surface in this desert were ignored, given their large coverage and wide distribution (Zhang et al., 2007). BSCs last the whole year and protect sandy soil surfaces from wind and water erosion (Zhang et al., 2006). BSCs might serve as the main biological factors for maintaining soil surface stability in this desert.

In recent years, our group has focused on studies of the formation, development and ecological roles of BSCs in the Gurbantunggut Desert. It is necessary for researchers or ecosystem managers in this region to get general information about BSCs in the desert. Hence the present paper summarizes our various research outcomes and aims to highlight the fundamental roles of BSCs in arid ecosystems.

\section{Study area}

The Gurbantunggut Desert is situated in the center of the Junggar Basin, Xinjiang Uygur Autonomous Region of China. It is the second largest desert in China with an area of $48.8 \times 10^{3} \mathrm{~km}^{2}$. Because of the "blocking effect" of the Himalayan Range, the moist air currents from the Indian Ocean fail to reach the area, resulting in the vast expanse of arid terrain. The mean annual precipitation is approximately $79.5 \mathrm{~mm}$, falling predominantly during spring. The mean annual evaporation is $2,606 \mathrm{~mm}$. The average annual temperature is $7.26^{\circ} \mathrm{C}$. The wind speeds are greatest during late spring each year, with an average velocity of $11.17 \mathrm{~m} / \mathrm{s}$, and come predominantly from west-northwest, northwest and north directions.

The natural vegetation in the area is dominated by Haloxylon ammodendron and $H$. persicum, with a vegetation cover of less than $30 \%$. The area is covered by huge and dense semi-fixed sand dunes with stable moisture content. There are abundant BSCs on the sand soil surface of the desert, growing especially during wet and cool seasons (early spring and autumn) when dew, fog or rain are available to species that form soil crusts (Du, 1990; Kidron et al., 2002; Zhang et al., 2002). The study was conducted in the southern part of the Gurbantunggut Desert where it contains representative BSCs (Zhang et al., 2002, 2004) (Fig. 1).

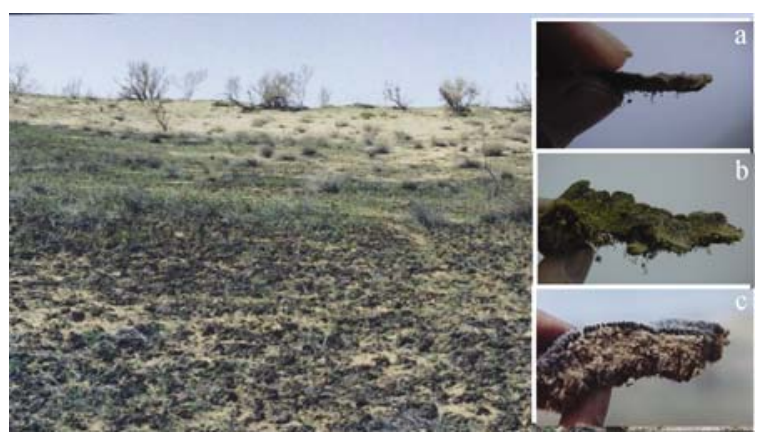

Fig. 1 Landscape of the Gurbantunggut Desert (left) and different types of BSCs (a: algae dominated crust; b: lichen dominated crust; c: moss dominated crust)

\section{Methods}

\subsection{Soil physiochemical characteristics}

Soil analyses were performed at the soil physiochemical analysis laboratory at Xinjiang Institute of Ecology and Geography, Chinese Academy of Sciences, using standard soil analysis procedures (Chen et al., 2007).

\subsection{Cross-section investigation and sample collec- tion}

Twenty typical sand dunes with geomorphologic structure and vegetation distribution evenly distributed in the study area were selected. At each site, seven plots $\left(1 \mathrm{~m}^{2}\right.$ in area) were positioned on sand dunes in three specific locations: i.e. leeward slopes of sand dunes, windward slopes of sand dunes and inter-dune areas. In order to acquire original soil samples, we used cutting ring to collect the intact biological soil crusts in the quadrats.

\subsection{Morphology and mineralogical component analysis}

The samples for making thin sections were dried at $45^{\circ} \mathrm{C}$ for $48 \mathrm{~h}$. Undisturbed soil samples were impregnated with a mixture of $1,000 \mathrm{ml}$ of epoxy resin and $130 \mathrm{ml}$ of catalyst (Triethanolamine), and saturated samples were dried at $65^{\circ} \mathrm{C}$ for $24 \mathrm{~h}$. The blocks of hardened soils were mounted on frosted microscope slides, cut to about $500 \mu \mathrm{m}$ thickness by a diamond-edged saw, and then polished to about $30 \mu \mathrm{m}$ thickness. Observations of the microstructures of thin sections were performed on an Olympus System Microscope (DP70, Models BX52, Olympus Corp, Ja- 
pan), and mineral particles in the $0-1 \mathrm{~cm}$ superficial layer were counted using a Nikon microscope (E-600, Nikon Corp, Japan). Observations of the microstructures of sand particles were performed under a LEO1430VP Scanning Electron Microscope (SEM, LEO Corp, Germany).

The texture of the $0-1 \mathrm{~cm}$ soil layer was determined using a laser grain-size analyzer (MasterSizer2000, UK). Samples were treated with hydrogen peroxide to remove organic matter, and then dispersed using ultrasound and sodium hexameta-phosphate.

\subsection{Wind tunnel tests}

For wind tunnel tests, undisturbed, well-developed soil surface crust samples were excavated in open interspaces between perennial vegetation. Undisturbed crust samples $(20 \mathrm{~cm} \times 30 \mathrm{~cm}$ and $12 \mathrm{~cm}$ thick) from the sandy soil surface were collected using metal boxes, prepared for wind tunnel tests. The experiments were carried out in a wind tunnel in the Key Laboratory of Desert and Desertification, Chinese Academy of Sciences.

\subsection{Measurements of dew deposition and produc- tion}

The observation areas were in inter-dune areas in the Gurbantunggut Desert. Micro-lysimeters were pushed into the soil to collect undisturbed soil columns covered by representative biological soil crusts. Bare sand columns were taken for controls. Their edges were close to the flat ground surface and their bases were covered.

Soil samples were exposed to the open air and weighed by a portable sensitive balance $( \pm 0.01 \mathrm{~g})$ powered by batteries at sunset (19:00) and before sunrise (7:00). The dew amount on a certain day is determined by the difference between the weights in the morning and that of the past sunset. By weighing the micro-lysimeters at regular intervals $(30 \mathrm{~min})$, the drying processes during the early-morning could be determined as well. An intensive observation of dew formation was conducted at 2-hour measurements between May 18 and 23 in 2008. The quantity of dew precipitation was calculated from the weights. Dew quantities were measured using micro-lysimeters with a diameter of $6 \mathrm{~cm}$ and a height of $3.5 \mathrm{~cm}$.

\section{Results and discussion}

\subsection{Species composition of BSCs in the Gurban- tunggut Desert}

The sand surface of this desert was covered by BSCs, i.e. microbial communities, dominated by filamentous cyanobacteria, lichen and mosses, which had been turned into hard, crust-like structures because of the severely desiccated conditions in which they survive. BSCs in this study area were heavily dominated by lichen species, with occasional lichen and moss patches in inter-dune areas.

4.1.1 Species composition of algae (cyanobacteria)

Microalgal diversity varied slightly during different BSCs' successional stages. Thirty-four microalgal species representing 23 genera and 17 families were identified in bare sand land. In algal crusts, 35 microalgal species representing 22 genera and 15 families were detected. Lichen crusts supported 36 microalgal species representing 23 genera and 15 families. Thirty-eight microalgal species of 22 genera, comprising 14 families, were observed in moss crusts. Cyanobacteria dominated in different successional stages and the number of cyanobacterial species identified was $25,25,28$, and 31 in bare sand land, microalgal, lichen, and moss crusts, respectively. Green microalgae, diatoms, and euglenoids were also detected, but they were less abundant than cyanobacteria.

Each successional stage showed changes in microalgal species composition. The most common species supported by bare sand land were Fragilaria sp., Amphora ovalis, Oscillatoria sancta, Microcoleus vaginatus, Phormidium okenii, and Palmellococcus miniatus. Diatoms, especially a species of Fragilaria, were more abundant in bare sand land than in other successional stages. M. vaginatus was abundant in all samples, but in a smaller range than Fragilaria. Synechococcus parvus, O. subbrevis, $P$. retzli, $P$. irriguum, Tychonema granulatum, $M$. vaginatus, $P$. miniatus, Fragilaria sp. and A. ovalis were common in microalgal crusts (Table 1). In lichen crusts, O. willei, $P$. retzli, $M$. vaginatus, Scytonema ocellatum, $P$. miniatus, and $C$. humicola were the most common species with a prevalence of $M$. vaginatus, S. ocellatum, and $P$. irriguum. In most cases, $M$. vaginatus was the first colonizer. With the exception of S. parvus, the common species of lichen crusts were also common 
Table 1 Taxonomic composition of the algal communities in different sand dune locations

\begin{tabular}{|c|c|c|c|c|}
\hline Locations & $\begin{array}{l}\text { Interdune } \\
\text { areas }\end{array}$ & $\begin{array}{c}\text { Windward } \\
\text { of sand } \\
\text { dunes }\end{array}$ & $\begin{array}{c}\text { Leeward } \\
\text { of sand } \\
\text { dunes }\end{array}$ & $\begin{array}{c}\text { Top of } \\
\text { sand } \\
\text { dunes }\end{array}$ \\
\hline Chroococcus minutus & + & + & + & + \\
\hline Chroococcus westii & + & - & + & - \\
\hline Chroococcus turgidus & + & + & + & - \\
\hline $\begin{array}{l}\text { Chroococcus turgidus var. } \\
\text { solitarius }\end{array}$ & + & + & + & + \\
\hline Cyanothece aeruginosa & + & + & + & + \\
\hline Synechococcus parvus & + & + & + & + \\
\hline Synechocystis crass & + & + & + & + \\
\hline Aphanocapsa montana & + & + & + & + \\
\hline Gloeocapsa sp. & - & + & + & + \\
\hline Jaaginema pseudogeminata & + & + & + & + \\
\hline Schizothrix friessi & + & - & - & - \\
\hline Oscillatoria formosa & + & + & + & + \\
\hline Oscillatoria tenuis & + & + & + & + \\
\hline Oscillatoria sancta & + & + & + & + \\
\hline Oscillatoria cortiana & + & + & + & + \\
\hline Oscillatoria chlorina & + & + & + & + \\
\hline Oscillatoria anguina & + & + & - & - \\
\hline Oscillatoria subbrevis & + & + & + & \\
\hline Lyngbya majuscula & + & + & - & - \\
\hline Lyngbya gracilis & + & + & - & - \\
\hline Phormidium gelatinosum & + & + & + & + \\
\hline Phormidium retzli & + & + & + & + \\
\hline Phormidium calcicola & - & - & - & + \\
\hline Phormidium okenii & + & + & + & - \\
\hline Phormidium attenuatum & + & + & + & + \\
\hline Tychonema granulatum & + & - & + & + \\
\hline Planktothrix cryptovaginata & + & - & + & + \\
\hline Microcoleus vaginatus & + & + & + & + \\
\hline Scytonema ocellatum & + & + & - & + \\
\hline Nodularia spumigena & + & + & - & + \\
\hline Nodularia sp. & + & + & + & + \\
\hline Nostoc commune & + & - & + & + \\
\hline Chlamydomonas ovalis & - & + & + & + \\
\hline Chlamydomonas sp. & + & + & + & + \\
\hline Chlorella vulgaris & + & + & + & + \\
\hline Palmellococcus miniatus & + & - & + & + \\
\hline Chlorococcum humicola & + & + & + & + \\
\hline Ulothrix tenerrium & + & - & + & + \\
\hline Fragilaria sp. & + & + & + & + \\
\hline Pinnularia borealis & + & - & - & - \\
\hline Hantzschia amphioxys & + & + & + & + \\
\hline Amphora ovalis & + & + & + & + \\
\hline Euglena sp. & + & + & - & + \\
\hline Lepocinclis sp. & + & + & - & - \\
\hline Petalomonas sp. & - & - & + & - \\
\hline Total & 41 & 35 & 35 & 34 \\
\hline
\end{tabular}

Note: + existent species, - absent species in moss crusts. Generally, S. ocellatum or P. miniatus were the initial colonizers, and $M$. vaginatus was the second.

4.1.2 Species composition of lichen and moss

Lichen species are the primary type and the most dominant components of BSCs in this desert, with occasional moss patches in interdune areas. Soil lichens occur as dense patches in the Gurbantunggut Desert. The most common lichens include Collema tenex, Psora decipiens, Xanthoria elegans, Acarospora strigata and Lecanora argopholis. Other less common lichens include Diploschistes muscorum, Heppia lutosa, Catapyrenium sp. and Caloplaca songoricum. The lichens in the desert usually present black, white, brown, yellow or blue according to species (Table 2).

Soil moss species are limited, and Syntrichia caninervis and Bryum argenteum are the most common in the desert. Other frequent mosses include Crassidium chloronotos and Tortula muralis (Table 3).

Table 2 The lichen species composition of BSCs in the Gurbantunggut Desert

\begin{tabular}{|c|c|c|}
\hline Family & Genus & Species \\
\hline \multirow{2}{*}{ Thelotremataceae } & Diploschistes & $\begin{array}{l}\text { Diploschistes muscorum (Schreb.) } \\
\text { Norm. }\end{array}$ \\
\hline & Fulgensia & Fulgensia bracteata (Hoffm.) Raws. \\
\hline \multirow{2}{*}{ Teloschistaceae } & Xanthoria & Xanthoria elegans (Link) Th.Fr. \\
\hline & Caloplaca & Caloplaca songoricum A. Abbas \\
\hline Psoraceae & Psora & Psora decipiens (Ehrh.) Hoffm.. \\
\hline Collemataceae & Collema & $\begin{array}{l}\text { Collema tenax var. corallinum } \\
\text { (Massal.) Degel., Collema tenax (Sw.) } \\
\text { Ach. }\end{array}$ \\
\hline Candelariaceae & Candeleriella & Candeleriella aurlla (Hoffm.) Zahlbr \\
\hline Lecanoraceae & Lecanora & Lecanora argopholis (Ach.) Ach. \\
\hline Physciaceae & Dimelaena & Dimelaena oreina (Ach.) Norman \\
\hline Lecideaceae & Lecidea & Lecidea slabens Fr. \\
\hline Acansporaceae & Acarospora & Acarospora strigata (Nyl.) Jatta \\
\hline Verrucariaceae & Catapyrenium & Catapyrenium perumbratum (Nyl.) Wei \\
\hline
\end{tabular}

Table 3 The moss species composition of BSCs in the Gurbantunggut Desert

\begin{tabular}{lll}
\hline Family & Genus & Species \\
\hline \multirow{2}{*}{ Pottiaceae } & Tortula & $\begin{array}{l}\text { Tortula muralis Hedw., Tortula muralis } \\
\text { var. aestiva Brid. ex Hedw. }\end{array}$ \\
& Crossidium & Crossidium chloronotos (Brid.) Limpr. \\
& Syntrichia & Syntrichia caninervis Mitt. \\
Bryaceae & Bryum & Bryum argenteum Hedw. \\
\hline
\end{tabular}




\subsection{The distribution patterns of BSCs in the Gurbantunggut Desert}

4.2.1 Selective distribution pattern of BSCs at sand dunes scale

Based on the observations of 20 typical sand dunes by cross-section investigation, species of algae are most abundant in the south of the desert, followed by the center part of the desert. Species of algae are rare in the western and eastern regions.

Some species are not selective in distribution and are the most common species in the desert, including Microcoleus paludosus, M. vaginatus, Xenococcus lyngbyge and Chroococcus turgidus var. solitarius. Most species are selective and only occur in particular sites in sand dunes. For example, Anabaena azotica, Lyngbya martensiana, Stigonema ocellatum, Amphora ovalis, Chlamydomonas mutabilis and Calothrix stagnalis are mostly observed on the interdune areas. Species such as Phormidium faveolarum, Microspora pachyderma, Oscillatoria princes and Scenedesmus bijuga are mostly found on the top of the sand dunes. The windward slopes of sand dunes are mostly dominated by cyanobacteria, such as Microcoleus paludosus, M. vaginatus, Scytonema crispum, Anabaena azotica and Scytonema crispum. The leeward slopes of sand dunes were found to be mostly dominated by green algae, such as Chlorella vulgaris, Chlorococcum humicola, Microspora pachyderma, Palmellococcus miniatus, Chlamydomonas mutabilis and Scenedesmus bijuga (Table 1).

The lichens on the west slopes of sand dunes grow better than those on the east slopes, while the distribution towards the top of the sand dune is limited. In the large area between sand dune slopes and the inter-dune areas, lichens dominated the cover by BSCs but were developed sporadically. BSCs dominated by lichens developed best in the south of the desert, followed by the middle and north parts. In the west of the desert, they developed with small areas only on the interdune areas and vanish on the east part.

Most of the mosses may be found only under the canopy of vascular plants, such as Haloxylon persicum and Ephedra distachya, where some protection from sand cover and strong sunlight are provided. In these microhabitats, there is more available water, decreased UV light penetration, and more favorable temperatures for moss to grow. Unlike other deserts in the United States and Australia, liverworts are quite uncommon under such canopy in the Gurbantunggut Desert.

4.2.2 Spatial distribution patterns of BSCs at whole desert scale

By combining remote sensing and field measurements, a new index of BSCs was developed in order to simulate the spatial distribution of BSCs in the Gurbantunggut Desert (Chen et al., 2005). Figure 2 shows the spatial distribution patterns of BSCs at the whole desert scale. The distribution of BSCs in the study area may be characterized at the following two aspects: (1) BSCs are mainly distributed in the south of the desert, where BSCs are mostly abundant and developed quite well. The second most abundant areas for BSCs occur in the middle and north parts. In the east, the ground surface is characterized by shifting or semi-shifting sand, where we found no occurrence of BSCs. BSCs are also developed in the region between the middle and west of the desert, but the distribution is fragmented and BSCs only occur in small area. The BSCs are not apparent from Shixi oil field to the west of Mosowan town. (2) BSCs are continuously distributed in the south of the desert, but their distribution patterns become patchy in the northern, western and eastern regions. The distribution characteristics of BSCs from Landsat ETM+ images coincided with our field observations. By counting pixels of BSCs' distributions, we found that BSCs occupied $33 \%$ of pixels, which accounts for $28.7 \%$ of the total study area (Fig. 2). Because the lowest

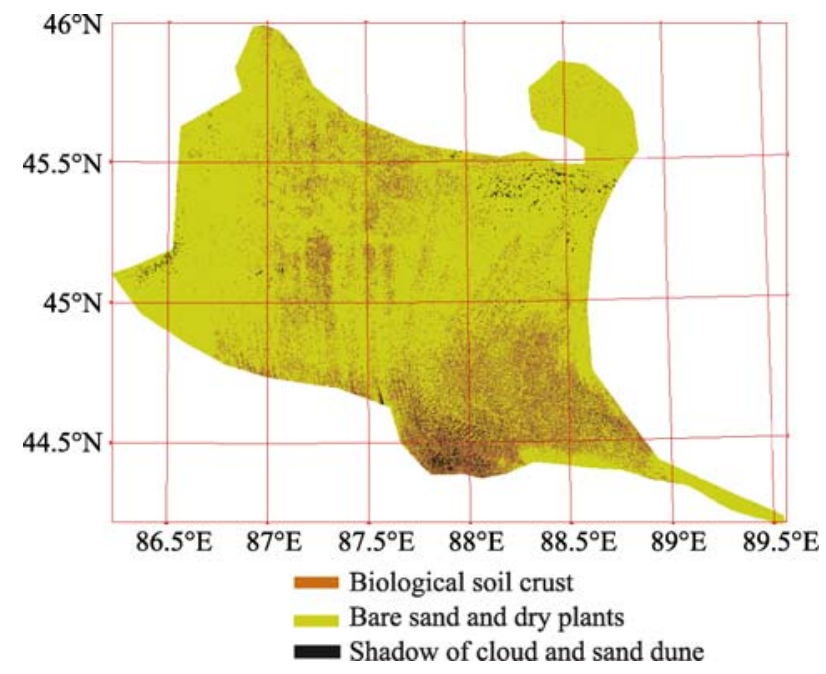

Fig. 2 The spatial distribution of BSCs in the Gurbantunggut Desert 
coverage of BSCs that the Landsat ETM+ sensor can detect is $33 \%$, the statistic result may underestimate the total area of BSCs in the study area.

\subsection{Ecological functions of BSCs in the Gurban- tunggut Desert}

4.3.1 Effects of BSCs on mineral weathering and desert soil formation

Increasingly complex life forms were found in older successional stages of BSCs in the Gurbantaunggut Desert. These crusts may play a critical role in mineral breakdown and desert soil formation by modifying the weathering environment and ultimately affecting mineralogical variance.

The minerals that are resistant to weathering like quartz and feldspar (plagioclase and K-feldspar) decreased with crust successions, whereas the pyroxene and hornblende that weather easily increased with crust successions (Fig. 3). Variability in quartz content is apparently related to crust development. Its content decreased from $56.1 \%$ in the surface of shifting sand to $52.0 \%, 52.5 \%, 49 \%$ and $49 \%$ in the crust of light
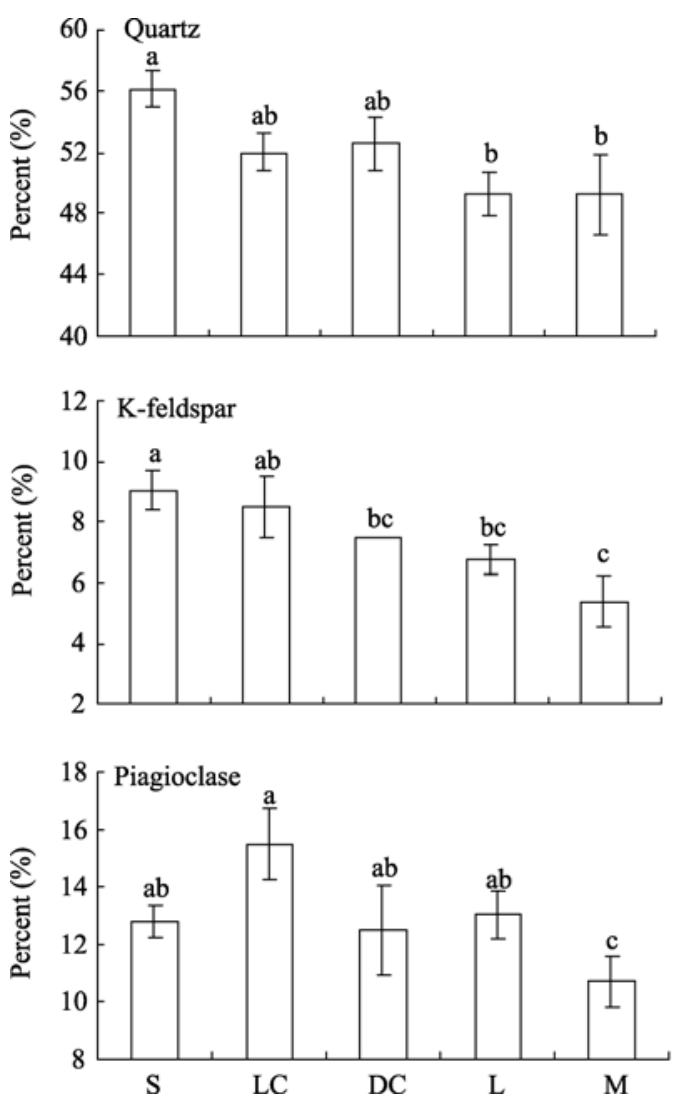

Fig. 3 The variance of main mineral contents of the successional crusts. Abbreviations, S, LC, DC, L, and M indicate shifting sand, light cyanobacterial crust, dark cyanobacterial crust, lichen crust and moss crust, respectively. Categories with different lower case letters differ significantly at $P<0.05$. Error bars indicate standard error. cyanobacteria, dark cyanobacteria, lichen and mosses, respectively. The quartz content did not differ significantly among shifting sand and the crust of light or dark cyanobacteria, whereas quartz content of shifting sand was significantly higher than that in the crusts of lichen and mosses. K-feldspar has the same trend as quartz. Among four types, K-feldspar content was highest in shifting sand (9.1\%), followed by light cyanobacterial crust (8.5\%), lichen (6.8\%) and mosses $(5.3 \%)$. Plagioclase content variability is not obviously related to crust succession. Its content was highest in light cyanobacterial crust (15.5\%), and did not differ significantly in shifting sand (12.8\%), dark cyanobacterial (12.5\%) and lichen (13.0\%). Mosses had dramatically lowest plagioclase content $(10.7 \%)$ than the other crust successions. The hornblende content increased with the development of crusts. Its content was the lowest in shifting sand (1.2\%), followed by light cyanobacterial crust $(1.6 \%)$ and dark cyanobacterial crust $(1.9 \%)$. The hornblende contents of lichen and mosses are $2.0 \%$ and $2.1 \%$, respectively,
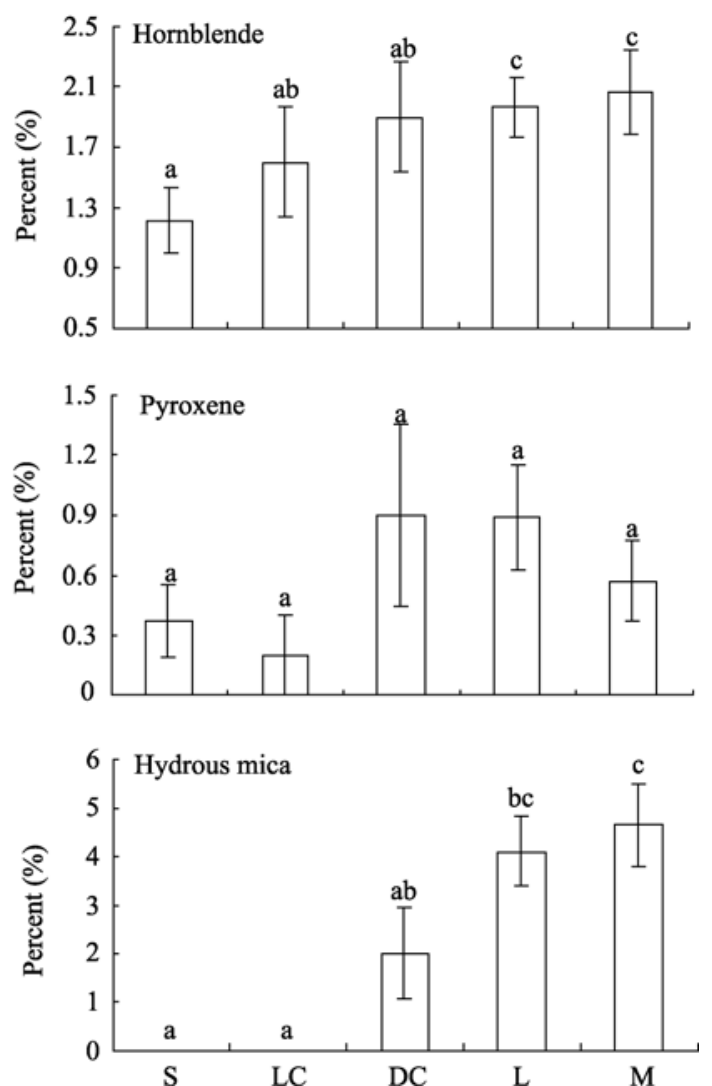
which is more significant than for the other three types. Successional crusts did not differ significantly in pyroxene content, but the late stages of successional crust (dark cyanobacterial crust, lichen and mosses) have higher pyroxene content than the light cyanobacterial crust and shifting sand. Hydrous mica content increased with crust successions. The highest content of Hydrous mica was found associated with mosses (4.6\%), followed by lichen $(4.1 \%)$ and dark cyanobacterial crust (2\%), whereas it was not found in the soil samples of shifting sand and light cyanobacterial crust.

It is known that cyanobacteria, lichen and moss erode and etch rocks, and secondary minerals produced by weathering were localized with the living organisms. Thus, more developed crusts appeared to contribute to greater mineral weathering and may be a major cause of mineral variance in the Gurbantunggut Desert (Fig. 4).

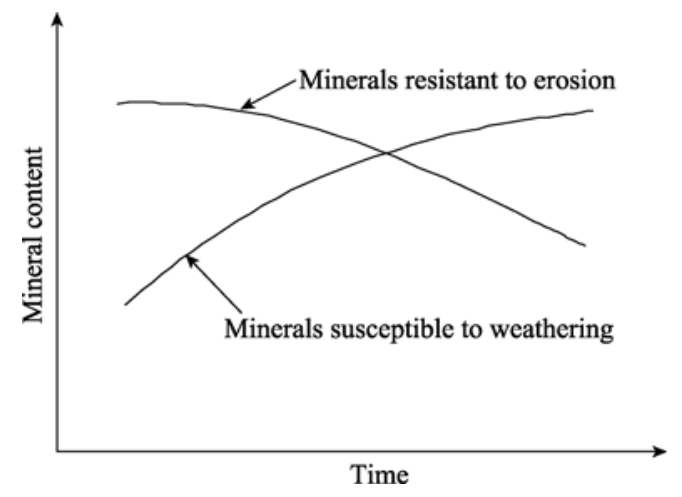

Fig. 4 Variation of mineral composition with the development of BSCs

The greater activity and complexity of older crusts, as well as their improved moisture condition may accelerate mineral weathering. Therefore, protection and recovery of BSCs are vital for desert soil formation.

\subsubsection{Resistance of BSCs to wind erosion}

Resistance to wind erosion paralleled the different disturbance levels of BSCs. Disturbances to sandy soil surfaces resulted in greatly decreased resistance to wind erosion (Fig. 5). Maximum wind tunnel velocity in this experiment $(25 \mathrm{~m} / \mathrm{s})$ did not lead to any wind erosion on the soil surface of undisturbed BSCs, i.e. $100 \%$ covered by crusts. As for different disturbance levels, the highest threshold friction velocities (TFVs) were seen in the sand soil surface with $10 \%$ disturbance of BSCs. The crust with $10 \%$ disturbance had
TFVs of $16.04 \mathrm{~m} / \mathrm{s}$ compared to $8.42 \mathrm{~m} / \mathrm{s}$ for bare sand and $8.74 \mathrm{~m} / \mathrm{s}$ for $100 \%$ disturbance of BSCs; consequently, coverage of $10 \%$ crust had about two times the wind resistance of bare sand. When $20 \%$ of the crust surface was disturbed, the TFVs decreased sharply to $12.27 \mathrm{~m} / \mathrm{s}$ and then became gradually closer to the TFVs of bare sand with increasing BSC disturbances. This indicated that the BSCs gradually lost their ability to resist wind erosion. Figure 5 indicates that three types of disturbance in this desert can be identified as: (i) slight disturbance: $0 \%-10 \%$ destruction of soil crust surface; (ii) moderate disturbance: $20 \%-60 \%$ destruction of soil crust surface; and (iii) severe disturbance: $80 \%-100 \%$ destruction of soil crust surface.

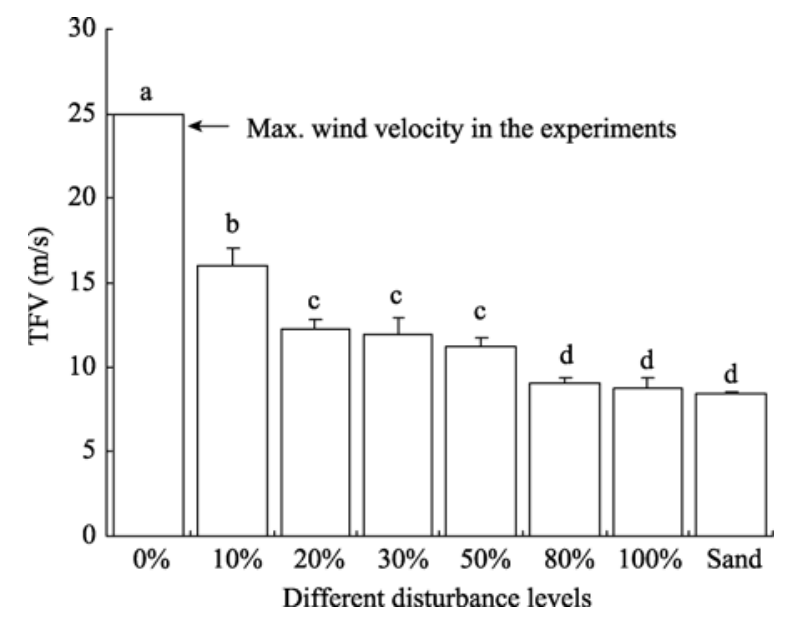

Fig. 5 Threshold friction velocities (TFVs) for microbiotic crusts at different disturbance levels. Categories with different lower case letters differ significantly at $P<0.05$. Error bars indicate standard error.

In all casaes of disturbance of BSCs, there was virtually no wind erosion at the wind speeds less than 6 $\mathrm{m} / \mathrm{s}$, while wind erosion began at a velocity around 10 $\mathrm{m} / \mathrm{s}$. The results showed that the rate of wind erosion increases with increasing levels of crust disturbance, suggesting that BSCs are one of the factors responsible for reducing wind erosion from the biologically fixed sandy soil in desert ecosystems. The surface condition of BSCs has a marked effect on wind erosion rates. Wind erosion rates for sandy soil with no crust cover was about 46,21 and 17 times the soil with $90 \%$ crust cover at wind velocities of 18,22 and 25 $\mathrm{m} / \mathrm{s}$, respectively. These results demonstrate that soil crusts can effectively control wind erosion. The reduction of trampling on the soil will eventually result in 
the re-establishment of BSCs and their associated organisms, and ultimately lead to lower levels of wind erosion.

4.3.3 Increase of organic matter content in the soil surface of desert ecosystems

The soil organic matter (SOM) content was found to gradually decrease from interdune areas to the tops of sand dunes in each soil layer in the Gurbantunggut Desert. The SOM contents in the interdune areas were higher than those on the slopes and tops of sand dunes. At each location on the sand dunes, the SOM was mainly distributed in the surface $0-5 \mathrm{~cm}$ soil layer with or without crust cover. This is the general distribution pattern of SOM in this desert. However, further ANOVA analysis shows that the occurrence of BSCs in the Gurbantunggut Desert could significantly enhance the accumulation of SOM in the surface 0-5 $\mathrm{cm}$ soil layer compared with the areas devoid of crust cover $(P<0.01)$. There is no significant difference for SOM content between $5-10 \mathrm{~cm}$ and $10-30 \mathrm{~cm}$ soil layers. That means the BSCs can only influence the accumulation of SOM in the $0-5 \mathrm{~cm}$ soil layer. Although the influence of biological crust on SOM content was only displayed in the surface $0-5 \mathrm{~cm}$ soil layer, the crust is likely to positively serve as an important nutrient input to the whole desert ecosystem due to its large coverage in the Gurbantunggut Desert. Particularly, the intensive accumulation of SOM in the surface $0-5 \mathrm{~cm}$ layer would be beneficial to the

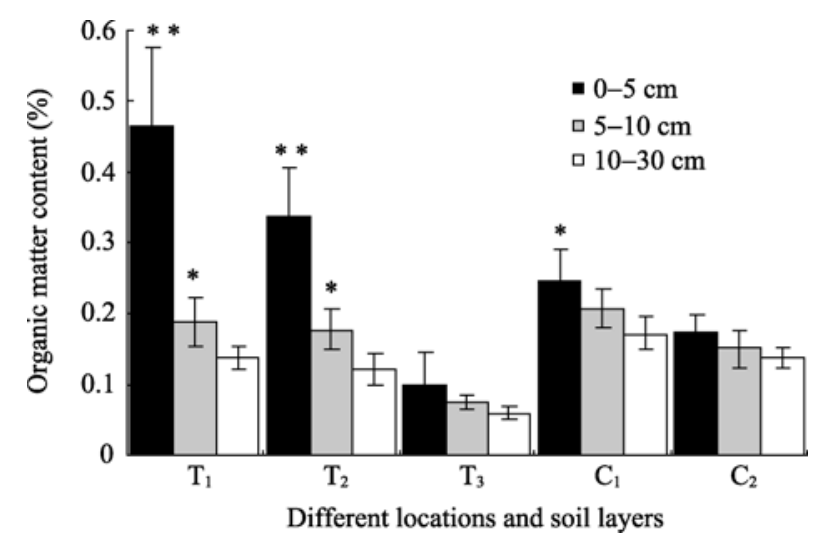

Fig. 6 The change of soil organic matter content in different soil layers from different location of sand dunes. * indicates the significant difference at $P<0.05$, ** indicates the significant difference at $P<0.01$. $\mathrm{T}_{1}, \mathrm{~T}_{2}$ and $\mathrm{T}_{3}$ mean moss-lichen crust from interdune area, algae crust from slope of sand dune and top of sand dune; $\mathrm{C}_{1}$ and $\mathrm{C}_{2}$ mean bare soil from interdune and bare soil slope of sand dunes. Error bars indicate standard error. growth of ephemerals and ephemeroids which are well-developed from early April to September in the Gurbantunggut Desert. Vascular plants contribute organic matter to soils directly beneath them; large interspaces between plants receive little input of plant material. However, soil organic matter contributed by BSCs helps to keep plant interspaces fertile, providing energy sources from soil microbial populations.

4.3.4 Effect of BSCs on seed germination of vascular plants

We selected five desert plants, Haloxylon persicum, Ephedra distachya, Ceratocarpus arenaarius, Malcolmia africana and Lappula semiglabra with different seed morphological characteristics in Gurbantonggut Desert to analyze the effects of BSCs on their seed germination.

The effects of BSCs on the germination of seed of these vascular plants with their different morphological characteristics were variable under both moist and

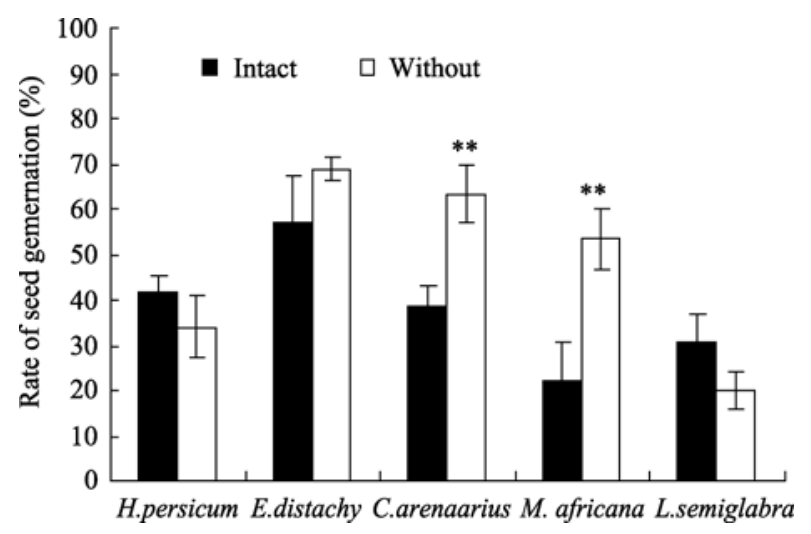

Fig. 7 The influence of BSCs on seed germination under dry condition. ${ }^{*}{ }^{* *}$ and bar indicate the same as Fig.6.

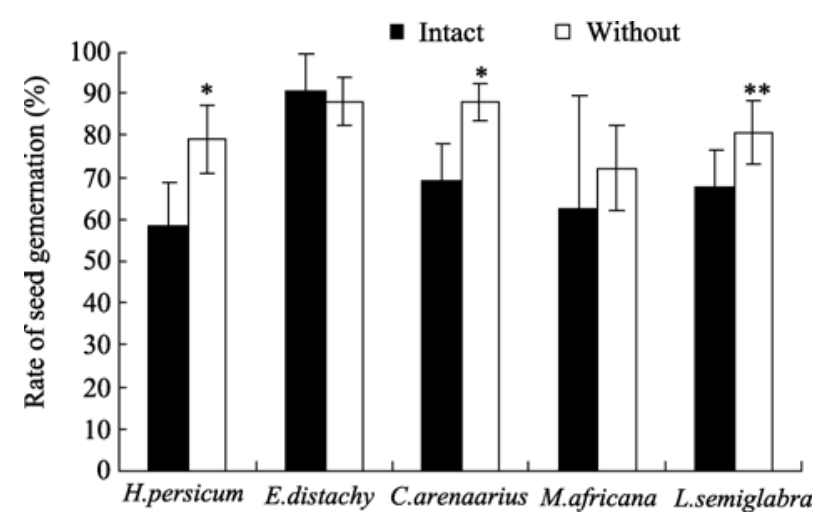

Fig. 8 The influence of BSCs on seed germination under wet condition. ${ }^{*}{ }^{* *}$ and bar indicate the same as Fig.6. 
dry conditions. The presence of crusts significantly reduced the germination of $C$. arenaarius and $M$. africana compared with surfaces from which the crusts had been removed. For the other three vascular plants, there was no significant effect on germination under dry conditions. Under moist conditions, the seed germination of $H$. persicum, $C$. arenaarius and $L$. semiglabra on crusts was significantly lower than that on a soil surface devoid of crusts, while for E. distachya and M. africana, there was no significant effect on germination (Figs. 7 and 8). In general, the BSCs can affect the generation of some plants. Whether that the effect is negative or positive mainly depends on both moisture condition and biological characteristics of the vascular plants.

\subsection{Effect of BSCs on the production of dew dep- osition}

The pattern of dew accumulation and evaporation was studied over eight mornings. Every morning condensation continued after dawn. This was clearly seen when the dew condensation and evaporation pattern was studied on May 8, 2008. Dew patterns for the following days for each surface category were very similar. The moss crust accumulated the greatest amount of dew, and then there was a substantial decrease in dew amounts for lichen and cyanobacterial crusts for which dew accumulation figures were similar, and finally a moderate decrease to the amount of dew accumulated by bare sand land.

Figure 9 shows the results of influence of different types of BSCs on dew production. For each type of crust studied, the maximum amount of dew recorded was several times greater than the minimum. Moss crust was characterized by having the greatest amount of dew at dawn and also the maximum amount of dew deposited, whereas bare sand yielded the lowest amount of dew, with lichen crust and cyanobacterial crust exhibiting intermediate values. However, this was not the case for dew duration, as bare sand retained moisture for the longest period of time, followed by cyanobacterial crust, moss crust and finally lichen crust. Dew continued to condense even after sunrise. The differences in dew deposition may be partially attributed to an effect of the BSCs on the surface area. This study demonstrates the important effect of BSCs upon dew deposition and may assist in evaluating the role of dew in arid and semi-arid envi- ronments

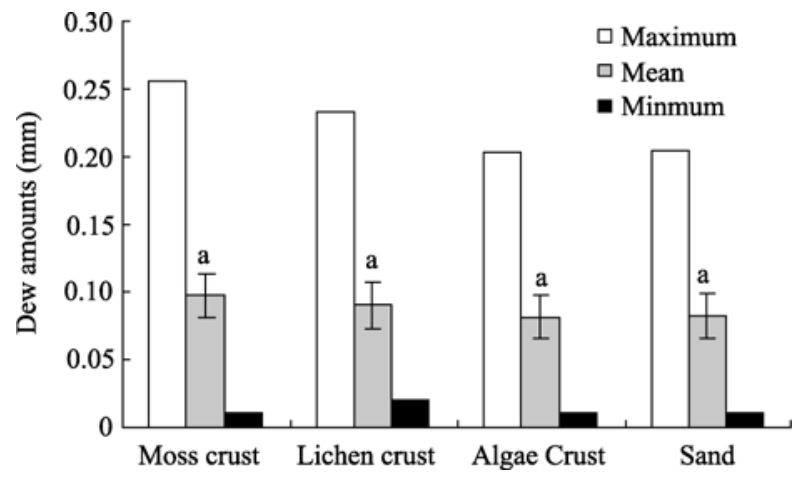

Fig. 9 Maximum, mean and minimum dew amounts on different ground surfaces, categories with the same letter have no significant differences at $P<0.05$.

\section{Conclusion}

Biological soil crusts typically consisted of a mixture of organisms including mosses, lichen, algae, cyanobacteria and microorganisms. Owing to their extraordinary abilities to survive desiccation, extreme temperatures, high solar radiation, high $\mathrm{pH}$, and high salinity environments, biological soil crusts have been found in desert areas worldwide.

As addressed by numerous studies, biological soil crusts play significant ecological roles in desert ecosystem. The presence of biological soil crusts improves soil formation, increases landscape stability and soil fertility, prevents soil erosion by water or wind, affects surface hydrological and nutrient cycles, contributes to carbon assimilation and nitrogen fixation, and enriches the diversity and abundance of insect species. In some studies, the biological soil crusts can also affect the germination and establishment of vascular plants.

BSCs cover is important for sand fixation in the Gurbantunggut Desert in northern Xinjiang, northwestern China. The network of filamentous cyanobacteria served as the main agent for surface stability. Additionally, the living filaments can migrate through the soil, leaving abandoned sheath material and a stabilized soil matrix behind. When undisturbed, the crusts are quite wind proof and with any disturbance, this resistance absolutely declines.

The recovery of the disturbed biological soil crust is very slow. On newly disturbed surfaces, mosses and lichens often have extremely slow colonization and 
growth rates. Therefore, effective measures should be taken to prevent disturbance to soil crusts of the fixed sandy soils. Inappropriate human activities, such as grazing, trampling by off-road vehicles, and ever-increasing recreational and commercial activities are resulting in unprecedented levels of local and regional disturbance, accelerating desertification processes. The human activities, such as livestock grazing and oil exploration have now become the main menaces to the stability of sand dunes in this desert, which disturb the fragile desert ecosystems, especially the BSCs. A reduction in trampling on the soil surface will eventually result in the re-establishment of bio-

\section{References}

Belnap J. The world at your feet: desert biological soil crusts. Frontiers in Ecology and the Environment, 2003, 1(5): 181-189.

Belnap J, Phillipsa S L, Witwickia D L, et al. Visually assessing the level of development and soil surface stability of cyanobacterially dominated biological soil crusts. Journal of Arid Environments, 2008, 72 : 1257-1264

Belnap J, Lange O L. Biological Soil Crust: Structure, Function, and Management. Berlin: Springer-Verlag, 2001. 5-12.

Chen J, Zhang Y M, Tamura M, et al. A new index for mapping lichen-dominated biological soil crust in desert areas. Remote Sensing of Environment, 2005, 96: 165-175.

Du X H. Study on topsoil crust in sandy land. Chinese Journal of Desert Research, 1990, 10: 31-37.

Eldridge D J, Greene R S B. Microbiotic soil crusts: a view of their roles in soil and ecological processes in the rangelands of Australia. Australia Journal of Soil Research, 1994, 32: 389-415.

Friedmann E I, Galun M. Desert algae, lichens and fungi. In: Brown G W. Desert Biology II, New York: Academic Press, 1974. 165-212.

Gray D W, Lewis L A, Cardon Z G. Photosynthetic recovery following desiccation of desert green algae (Chlorophyta) and their aquatic relatives. Plant, Cell and Environment, 2007, 30: 1240-1255.

Harper K T, Marbel G R. A role for nonvascular plants in management of arid and semi-arid rangeland. In: Tueller P T. Vegetation Science Applications for Rangeland Analysis and Management. Dordrecht: Kluwer Academic Publishers, 1988. 135-169.

Kidron G J, Herrnstadt I, Barzilay E. The role of dew as a moisture source for sand microbiotic crusts in the Negev Desert, Israel. Journal of Arid Environments, 2002, 52: 517-533. logical crusts and their associated organisms, and ultimately lead to lower levels of wind erosion. Therefore, specific actions including reduction in types and intensities of the use as well as adjustments in timing of use should be taken to ensure the sustainable management of the aeolian sandy soils in the Gurbantunggut Desert.

\section{Acknowledgements}

This work was supported by the Key Knowledge Innovation Project of the Chinese Academy of Sciences (KZCX2-YW-336), and the National Natural Science Foundation of China (40771114).

Li X R, Zhang Y M, Zhao Y G. A study of biological soil crusts: recent development, trend and prospect. Advances in Earth Science, 2009, 24(1): 12-24.

Qian Y B, Wu Z N, Zhang L Y, et al. Vegetation-environment relationships in Gurbantunggut Desert. Acta Ecologica Sinica, 2007, 27(7): 2802-2811.

Wang X Q, Jiang J, Lei J Q, et al. The distribution of ephemeral vegetation on the longitudinal dune surface and its stabilization significance in the Gurbantunggut Desert. Acta Geographica Sinica, 2003, 58(4): 598-605.

West N E. Structure and function of microphytic soil crusts in wildland ecosystems of arid to semi-arid regions. Advances in Ecological Research, 1990, 20: 179-223.

Zhang Y M, Cao T, Pan B R. A study on bryophyte associated with formation of soil crust in south fringe of Gurbantunggut Desert in Xinjiang, China. Acta Botanica Boreali-Occidentalia Sinica, 2002, 22: $18-23$.

Zhang Y M, Pan H X, Pan B R. Distribution characteristics of biological soil crust on sand dune surface in the Gurbantunggut Desert, Xinjiang. Journal of Soil and Water Conservation, 2004, 18: 61-64.

Zhang Y M, Wang H L, Wang X Q, et al. The microstructure of microbiotic crust and its influence on wind erosion for a sandy soil surface in the Gurbantunggut Desert of Northwestern China. Geoderma, 2006, 132: 441-449

Zhang Y M, Chen J, Wang L, et al. The spatial distribution patterns of biological soil crusts in the Gurbantunggut Desert, Northern Xinjiang, China. Journal of Arid Environments, 2007, 68: 599-610. 